\title{
ANÁLISE DAS MANIFESTAÇÕES PATOLÓGICAS NAS CALÇADAS CAUSADAS PELA ARBORIZAÇÃO URBANA
}

\author{
CARNEIRO, MAYCON \\ Graduando \\ Instituto Federal da Paraíba \\ Paraíba; Brasil \\ oliveiramaycon015@gmail.com
}

\author{
LIRA, MARCELO \\ Graduando \\ Instituto Federal da Paraíba \\ Paraíba; Brasil \\ mdaniellira@gmail.com
}

\author{
SILVA, DÉBORA \\ Graduando \\ Instituto Federal da Paraíba \\ Paraíba; Brasil \\ deborasilvacongopb@gmail.com \\ BRITO, WHELSON \\ Professor \\ Instituto Federal da Paraíba \\ Paraíba; Brasil \\ wbrito1313@gmail.com
}

\section{RESUMO}

Sabe-se que é indispensável a presença de árvores nas cidades, pois inúmeros são os benefícios que as mesmas trazem para a saúde da população, além de contribuir para a qualidade do ar e estética do meio urbano. Essa pesquisa tem como objetivo analisar as manifestações patológicas causadas pelas raízes das árvores e expor a opinião dos residentes da cidade de Monteiro sobre a arborização e os inconvenientes causados pela mesma. Para tal foram realizados exames visuais e fotográficos e aplicado um formulário com alguns moradores do centro da cidade. Diante do contexto proposto, pôde-se observar que a população tem consciência dos prós oferecidos pelas árvores, porém se incomoda com os contras. A falta de planejamento do plantio tem ocasionado diversos inconvenientes aos moradores, como por exemplo, a quebra de calçadas influenciadas pelas raízes, como também a destruição de encanamentos ou outros materiais próximos às árvores. Foram identificadas as espécies Ficus benjamina Linn, Peltophorum dubium e Acácia auriculiformis como principais responsáveis pelas manifestações patológicas. Analisou-se os tipos de prejuízos que as manifestações patológicas apresentam, tendo como base a opinião dos moradores e constatou-se que $20 \%$ prejudica o trafego de pessoas, 30\% apresenta possível invasão domiciliar e 50\% apenas degradação estética. Em algumas das situações houve tentativa de reparo na calçada, entretanto com raízes tão agressivas, as manifestações voltaram a aparecer, por esse motivo houve receio por parte dos moradores em optar por novos reparos/recuperação, onde $60 \%$ deles tentaram o reparo e $40 \%$ não optaram pelo reparo.

Palavras-chave: manifestações patológicas, calçadas, Monteiro-PB.

\section{ABSTRACT}

It is known that cities should have trees for they bring many benefits for the health of a population, including air quality and urban aesthetic. This research aims to analyze the pathologies caused by the tree roots and show the opinions of the residents of Monteiro city about afforestation and the nuisances caused by it. In order to do so, we did some visual examinations and applied a sheet with some residents from the city center. Based on that, we could verify that the population is aware of the advantages of having trees, however, they are bothered by their drawbacks. The lack of a planting plan is causing many nuisances to the residents, such as the destruction of the sidewalks, pipes or other materials near the tree roots. We have identified Phicus, Canafistula and Acacia as the main responsible for the pathological manifestations. Based upon the residents' opinion we have analyzed the types of damage caused by the pathologies and results indicated that $20 \%$ harms the traffic of people, $30 \%$ presents possible home invasion and $50 \%$ only causes aesthetic degradation. In some of the situations there was an attempt to repair the sidewalk, however with such aggressive roots, the demonstrations reappeared, for this reason there was fear on the part of the residents to opt for new repairs / recovery, where $60 \%$ of them tried to repair and $40 \%$ did not opt for repair.

Key words: pathologies, sidewalkstrees, Monteiro-PB. 


\section{INSTRUÇÃO}

A arborização engloba um conjunto de fatores, sendo grande responsável em atribuir vantagens para com a sociedade e centros urbanos. Entretanto, se não houver um estudo do plantio de espécies apropriadas e um manuseio adequado dessas espécies no momento do plantio, podem vir a causar desconforto e gerar manifestações patológicas nas edificações. Segundo Lopes; Teixeira (2017) pode-se definir o termo Patologia das Edificações como possíveis anomalias que surgem nas edificações tomando como exemplo lesões, defeitos e falhas.

O aumento da temperatura é uma das alterações climáticas favorecidas pelo ambiente construído devido às diferenças existentes entre as características térmicas dos materiais de construção e da vegetação (MARTELLI; SANTOS JR, 2015, p. 1018). Os benefícios econômicos indiretos são os de maior importância, como sua sombra e decorrente redução do consumo de energia por condicionadores de ar, onde a transpiração de uma árvore e, consequente diminuição de temperatura, consegue equivaler-se a cinco condicionadores de ar ligados, 20h/dia (VOLPE-FILIK, 2009 p. 23 apud GREY; DENEKE, 1986; SCHUBERT, 1979). O verde urbano possibilita a sustentabilidade da vida humana, é um indicativo da qualidade estética da cidade e reflete a biodiversidade dos ecossistemas urbanos (GONÇALVEZ; MANEGUETTI, 2015, p. 100).

Quando se trata da satisfação relacionada ao bem estar e harmonização do ambiente, as mudanças são divergentes ao se comparar um ambiente arborizado a um escasso de arborização. Desta maneira, a vegetação tem papel preponderante no conforto ambiental dos espaços urbanos, pois interfere diretamente na redução de temperatura do ar, de superfícies sombreadas, na umidade do ar e na redução da poluição atmosférica (MARTELLI; SANTOS JR, 2015, p. 1024). Segundo Dantas (2004) além de embelezar a cidade do ponto de vista estético, contribui através das qualidades plásticas como cor, forma e textura de cada parte visível de seus componentes, com sua capacidade de absorver o gás carbônico aumenta o teor de oxigênio e de umidade, está relacionada também ao aspecto psicológico do homem com a satisfação que ele sente ao ter contato com a vegetação.

O cultivo de árvores no semiárido nordestino é importante para o aumento da qualidade de vida da população, principalmente para amenizar a sensação térmica. As áreas verdes públicas deste município não representam bem a flora da Caatinga, bioma no qual está inserido, devido ao alto percentual de espécies exóticas e da baixa diversidade de espécies empregadas na arborização urbana, necessitando de um programa de arborização mais estruturado (BEZERRA; COSTA; SILVA, 2016).

Ainda segundo Bezerra; Costa; Silva (op cit) a espécie de maior frequência foi Fícus benjamina que representou 51,2 \% do total de espécimes inventariados. Essa espécie gera muitos problemas na arborização como o tombamento de outras árvores, rachaduras de calçamento e construções. Esta figueira exótica está sendo amplamente usada na arborização principalmente pelo rápido crescimento e desenvolvimento nas regiões áridas.

A região Nordeste do nosso país está em quarto lugar entre as regiões mais arborizadas, de acordo com o estudo do IBGE, as regiões mais arborizadas nos quarteirões, calçadas ou canteiros, concentram-se no Sudeste e no Sul do País, com 73,5\% e 72,1\% de cobertura, respectivamente. O Centro-Oeste, com 69,5\%, e o Nordeste, com 61,5\% ocupam posições intermediárias (JUNQUEIRA; PEETZ, 2012).

A calçada precisa ser considerada como a via por onde circula o modo de transporte mais frágil e mais numeroso em qualquer cidade (RENK, 2018, p.16). É definido como calçada parte da via, normalmente segregada e em nível diferente, não destinada à circulação de veículos, reservada ao trânsito de pedestres e, quando possível, à implantação de mobiliário, sinalização, vegetação e outros fins (NBR 9050). Segundo o Art. 68 do Código de Trânsito Brasileiro Lei 9503/97 a autoridade competente pode permitir o uso das calçadas para outros fins, desde que não seja prejudicial ao fluxo de pedestres.

Com o desenvolvimento das cidades, é cada vez maior a preocupação quanto à manutenção da qualidade de vida nestes centros urbanos, tendo a arborização urbana importância na melhoria de aspectos sanitários, sociais e estéticos. Nesse sentido, o estudo da problemática da existência de características indesejáveis às plantas e da compatibilização do espaço com os equipamentos públicos tem significativa relevância. (SILVA et al, 2019, p. 371).

O sistema radicular das plantas é o órgão responsável pela fixação dos vegetais e pela absorção de água e sais minerais. Tal sistema pode proporcionar significativas melhorias ao solo, especialmente nos aspectos relacionados à estrutura e 
no acúmulo de matéria orgânica no solo (SALTON e TOMAZI, 2014). Esse sistema também pode causar danos físicos às edificações, devido ao constante crescimento de suas raízes como também modificar o teor de umidade do solo. As raízes extraem água do solo para manter seu crescimento e vitalidade, modificando o teor de umidade do solo se comparado com o local onde as raízes não estão presentes. Se isso ocorre em solos argilosos há uma variação volumétrica, provocando recalques localizados na fundação e consequentemente fissuras na edificação (MILITITSKY; CONSOLI; SCHNAID, 2005, p. 34). As fissuras comumente vistas são inclinadas. Segundo Calisto; Koswoski (2015), $\mathrm{O}$ recalque é a principal causa de trincas e rachaduras em edificações, principalmente quando ocorre o recalque diferencial, ou seja, uma parte da obra rebaixa mais que a outra gerando esforços estruturais não previstos e podendo até levar a obra à ruína. Muitas vezes cometem-se erros irreparáveis pela má escolha da espécie a plantar, em geral, agravados pela desconsideração das necessidades e exigências elementares da vegetação, como as relacionadas ao solo, água, luz e ao ambiente (DANTAS; SOUSA, 2004).

A pesquisa teve como objetivo analisar as manifestações patológicas causadas pelas raízes das árvores e expor a opinião dos residentes da cidade de Monteiro sobre a arborização e os inconvenientes causados pela mesma.

\section{METODOLOGIA}

Diversas ruas foram visitadas no centro da cidade de Monteiro-PB para a coleta de dados. Segundo dados do Instituto Brasileiro de Geografia e Estatística-IBGE (2010), Monteiro é a maior cidade da Paraíba com 986,356 km², fica localizado no Cariri Ocidental Paraíbano e conta com 30.852 habitantes. O município apresenta clima semiárido, quente durante o dia e frio à noite.

No processo de vistoria foram observadas cento e nove calçadas, dentre elas foram selecionadas dez que apresentavam manifestações patológicas mais relevantes. Logo após procederam-se abordagens à medida que os residentes cooperavam. Houve aplicação de formulário junto a esses moradores, tão como a realização de exames visuais e fotográficos.

Formulário esse o qual contava com questionamentos simples a respeito dos prejuízos ou incômodos causados pelas raízes das árvores. As informações coletadas levaram em consideração os seguintes aspectos: espécie da árvore, material da calçada, desconforto causado pela manifestação patológica e manutenção corretiva (reparo). O levantamento dos dados ocorreram entre os dias 12 e 29 do mês de agosto do ano de 2019.

\section{RESULTADOS E DISCUSSÃO}

Durante o percurso nas ruas, foram coletadas informações de cento e nove calçadas, constando que sessenta e três possuiam arborização. Observou-se que é evidente a presença das manifestações patológicas provocadas pelas raízes das árvores de grande porte, a presença dessas em grande quantidade e com espaço entre elas relativamente pequeno trouxe danos às calçadas e sistemas das edificações. Sabe-se que não há grande diversidade de espécies na cidade, o que favorece a propagação de problemas.

Tabela 1- Comparação de calçadas arborizadas

\begin{tabular}{c|c|c}
\hline Especificações & $\mathrm{N}^{\circ}$ de Casos & Porcentagem \\
\hline $\begin{array}{c}\text { Calçadas arborizadas sem } \\
\text { fissuras/abaulamento }\end{array}$ & 15 & $23,8 \%$ \\
\hline $\begin{array}{c}\text { Calçadas arborizadas com } \\
\text { fissuras/abaulamento }\end{array}$ & 48 & $76,2 \%$ \\
\hline Total de calçadas arborizadas & 63 & $100 \%$ \\
\hline
\end{tabular}

Observou-se que $76,2 \%$ das calçadas análisadas apresentaram algum tipo de manifestação patológica. Com trinta e quatro dos casos provocados pela espécie Ficus benjamina Linn, comprova-se a predominância da espécie com número distante dos demais que apresentaram seis casos de Senna siamea, dois casos de Peltophorum dubium e seis casos de espécies distintas. Dentre as quarenta e oito calçadas que apresentaram manifestações patológicas, para o desenvolvimento da pesquisa foi feita a amostragem com dez que apresentavam manifestações patológicas aparentemente mais relevantes. 
Foi visto em abundância a espécie figo (Ficus benjamina Linn). Segundo Zea et al (2015), esta espécie exótica é encontrada em abundância no nordeste brasileiro pois tem o crescimento rápido e fácil adaptação a condições climáticas. Porém além de ter provocado perda de biodiversidade, não é indicada para plantio nas calçadas, pois tem rápido crescimento e pode atingir mais de 30 metros de altura, com um sistema radicular agressivo para as calçadas. $\mathrm{O}$ plantio do Ficus é recomendado para praças e jardins, desde que exista muito espaço e nenhuma pavimentação (CARVALHO et al, 2013). Em todas as calçadas em que havia a presença de tal espécie foi observado a presença de fissuramento.

Foi encontrada a espécie Canafístula, que segundo o Instituto Brasileiro de Floresta o nome científico é Peltophorum dubium, podendo atingir uma altura de até $25 \mathrm{~m}$, e diâmetro de até $70 \mathrm{~cm}$.

Por fim tem-se a Acácia amarela (Senna siamea), que conforme Dutra, et al (2007) é uma das espécies exóticas que se adaptou as condições do Nordeste brasileiro, é originada da Tailândia, sudeste da Ásia e vem sendo ultilizada no arboreo urbano.

Em três dos casos, os moradores não foram capazes de fazer a identificação, porém a partir de análise dos exames visuais e fotográficos, foi possível identificá-las, onde as espécies em dois dos casos eram fícus e no outro acácia.

Tabela 2- Espécies Encontradas

\begin{tabular}{c|c|c}
\hline Espécie & $\mathrm{N}^{\circ}$ de Casos & Porcentagem \\
\hline Ficus benjamina Linn & 7 & $70 \%$ \\
\hline Senna siamea & 2 & $20 \%$ \\
\hline Peltophorum dubium & 1 & $10 \%$ \\
\hline Total & 10 & $100 \%$ \\
\hline
\end{tabular}

Segundo Bezerra; Costa; Silva (2016), a fitogeografia da cidade de Monteiro mostrou que apenas 18,2\% são plantas nativas do território brasileiro, enquanto $81,8 \%$ são plantas exóticas que foram introduzidas na região oriundas de outras partes do mundo. Ao se considerar a abundância de espécies das 529 árvores inventariadas na cidade de Monteiro, apenas $13,1 \%$ representam a flora nativa da Caatinga, enquanto $86,9 \%$ pertencem a espécies exóticas.

Foram analisados os tipos de prejuízos que as manifestações patológicas poderiam causar a população, tal como o custo para a recuperação que requer aquisição de recursos como a compra de materiais e contratação de mão de obra para a realização do serviço. Apesar de tratar-se de uma área relativamente pequena a ser restaurada, é necessário a aquisição de uma grande parcela de materiais, tendo em vista que dificilmente são comercializados em porções, causando desperdício e acúmulo de material sem utilização. No mercado de trabalho atual alguns serviços são pagos por "diária", sendo assim a depender da complexidade do trabalho tende por ser inviável contratações para o desempenho da atividade.

Em relação ao tráfego de pessoas, sabe-se que a calçada deve ser considerada um local seguro aos pedestres levando em consideração as pessoas com deficiências físicas como cadeirantes e deficiêntes visuais. As calçadas e as travessias de pedestres constituem elementos essenciais para garantir a circulação segura e confortável das pessoas e assim ajudar nos deslocamentos realizados nas cidades (AGUIAR, 2003, p. 5). Porém com as raízes invadindo esse espaço arrisca-se a possibilidade da ocorrência de acidentes.

Além das calçadas, as raízes podem atingir diversos sistemas da edificação podendo prejudicar tubulações, o piso da residência e no mais grave dos casos afetando as fundações. A maioria das raízes ocupam cerca de 0,50 m da camada mais superficial do solo, sendo necessário adequar as espécies aos devidos espaços disponíveis ao plantio, caso contrário pode ocorrer diversos problemas nas calçadas (CARVALHO et al, 2013).

A figura 1 apresenta a escassez de um sistema adequado, como por exemplo um canteiro ao redor do tronco, para a infiltração das águas pluviais no solo, consequentemente originando a falta de espaço adequado para o desenvolvimento das raízes. Neste tipo de problema é inevitável o rompimento da calçada no momento de crescimento das mesmas. 


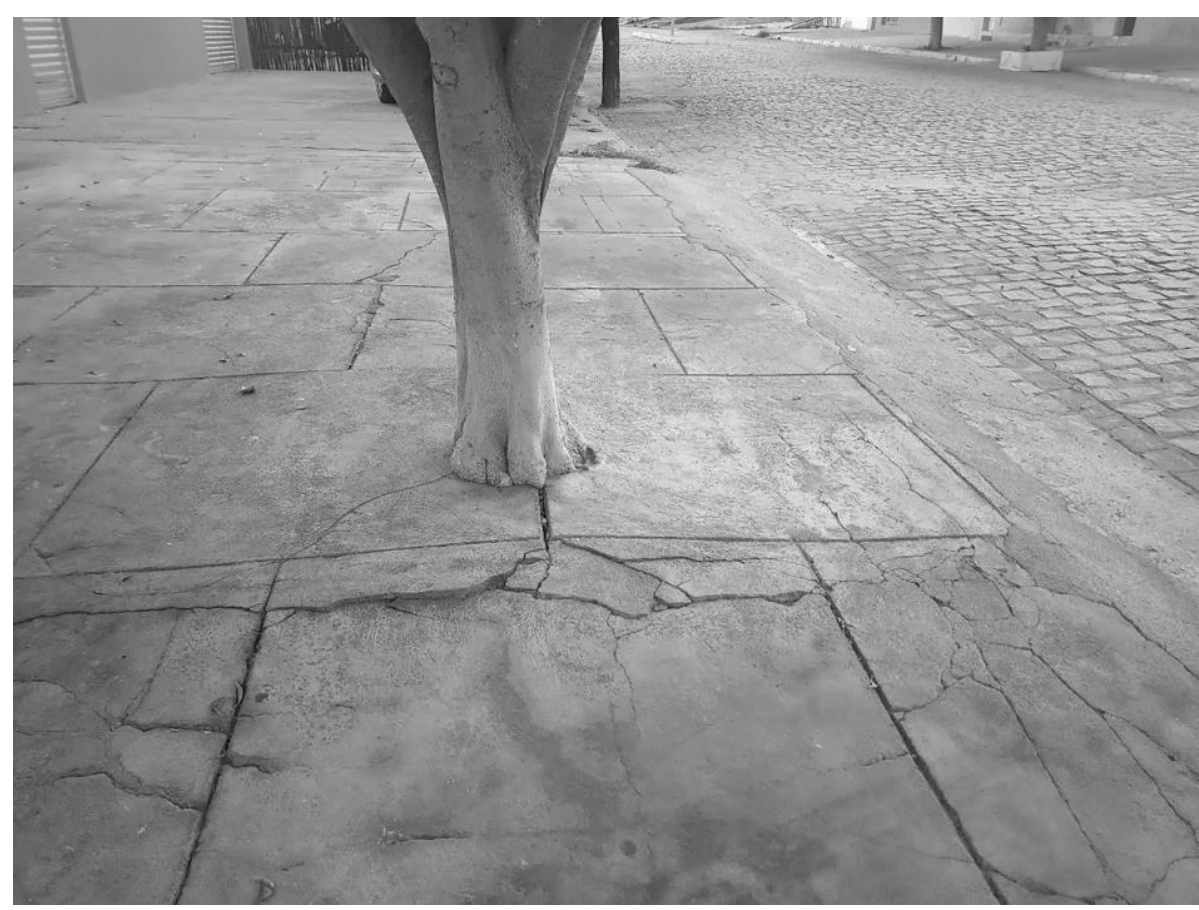

Figura 1: Falta de Canteiro

Dentre os dez casos analisados, sete mostraram-se afetados apenas na calçada enquanto três apresentaram-se com maior agressividade, sendo danosas tanto na calçada quanto no interior da residência. Um dos relatos sobre as edificações observadas, foi enfatizado que a presença de árvores ao redor desencadeou uma série de problemas, em que houve a invasão de raízes na tubulação de esgoto, chegando até o ralo do banheiro da residência, havendo a necessidade uma intervenção obrigatória para o conserto dos danos na encanação, piso e calçada. Em relação ao desconforto causado por tais manifestações patológicas, foram analisados como apenas esteticamente desagradavel, possível invasão domiciliar e prejudicial ao tráfego de pessoas.

Tabela 3- Prejuízos encontrados

\begin{tabular}{c|c|c}
\hline Tipos de Prejuízos & $\mathrm{N}^{\circ}$ de Casos & Porcentagem \\
\hline Apenas esteticamente & 5 & $50 \%$ \\
\hline Possível invasão domiciliar & 3 & $30 \%$ \\
\hline Prejudicial ao tráfego & 2 & $20 \%$ \\
\hline
\end{tabular}

Provem da análise dos dados que 60\% dos moradores efeturam algum tipo de manutenção/recuperação, atestando que o valor quantitativo necessário foi mediano entre as opções baixo, médio e alto, enquanto $40 \%$ dos casos não houve intenção da injeção de recursos ou tempo destinados para a manutençã/recuperação da calçada. Os materiais de que são feitas as calçadas também influenciam no custo e conserto, tendo em vista que o material cerâmico nem sempre é encontrado no mercado com o mesmo modelo, cor e tamanho que o já assentado anteriormente. As calçadas são os elementos que permitem a conexão do mundo interno com o externo, e o material com que são construídas fazem toda diferença (RENK, 2018, p.19).

Tabela 4- Tipos de revestimentos das calçadas

\begin{tabular}{c|c|c}
\hline $\begin{array}{c}\text { Materiais constituintes da } \\
\text { calçada }\end{array}$ & $\mathrm{N}^{\circ}$ de Casos & Porcentagem \\
\hline Argamassado ou concreto & 6 & $60 \%$ \\
\hline Placas pré-moldadas & 2 & $20 \%$ \\
\hline $\begin{array}{c}\text { Revestimento cerâmico } \\
\text { assentado sobre argamassa }\end{array}$ & 2 & $20 \%$ \\
\hline
\end{tabular}

Segundo Aranha (1994), a manutenção de estruturas de concreto pode ser entendida como o conjunto de ações de reduzido alcance, como forma de prevenir ou identificar o surgimento de danos (Manutenção preventiva) e, quando a estrutura apresentar perda significativa, como forma de se evitar o comprometimento da segurança da estrutura 
(Manutenção corretiva). Quando é feita a manutenção corretiva, por vezes é ineficiente, isso acontece devido à falta de eficácia no procedimento, onde tendem a reaparecer os eventos de fragmentação da calçada. Uma das situações chama atenção por aparentar grande abaulamento (levantamento) de parte da calçada, atingindo a entrada da residência.

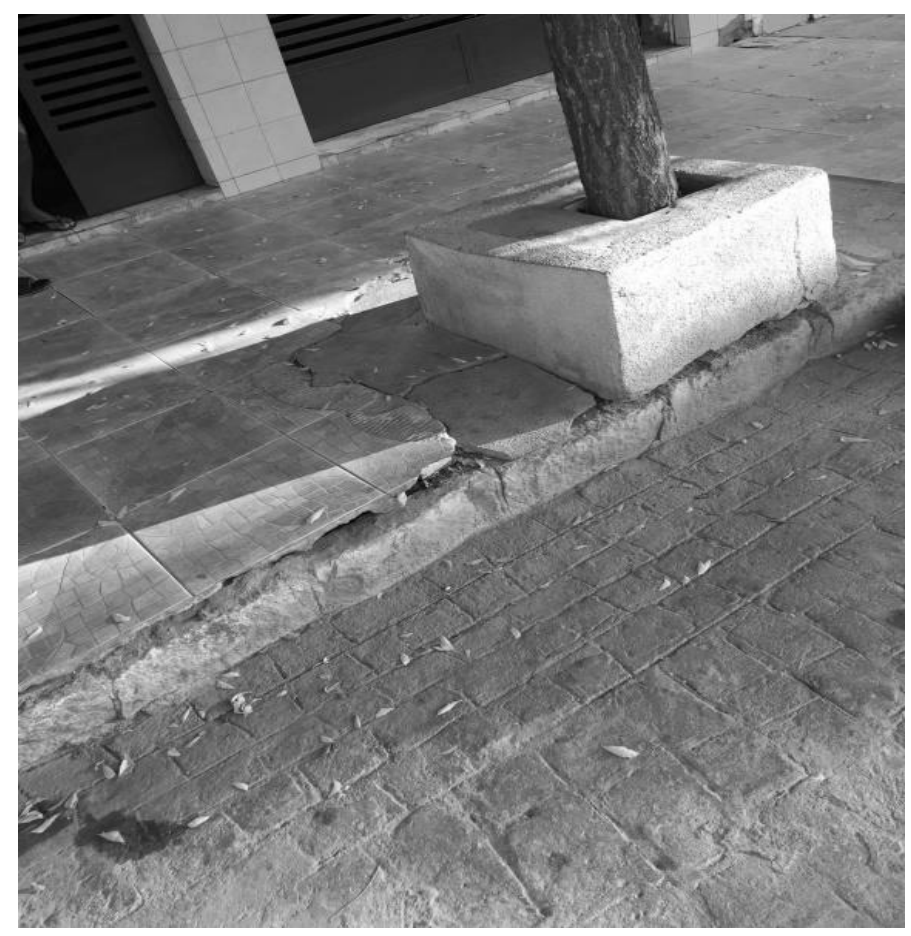

Figura 2: Abaulamento do piso da calçada

Os resultados encontrados foram consistentes em relação ao descontentamento dos indivíduos observados. Devido à persistência na aparição de empecilhos envolvendo a estrutura da calçada, tão como concomitante a ambientes internos da residência, à medida que os questionamentos se desenvolviam, viu-se a inquietação quando questionados a respeito dos danos causados, por serem de maneira ativa geradores de despesas não planejadas, além de transtornos quanto ao tempo de manutenção e estética da moradia.

\section{CONSIDERAÇÕES FINAIS}

O estudo obteve informações sobre as problemáticas e características das espécies Ficus benjamina Linn, Peltophorum dubium e Senna siamea, que são provavelmente as espécies predominantes plantadas na cidade. As manifestações patológicas encontradas foram fissuras e abaulamento (levantamento) nas calçadas, em algumas edificações no interior da residência houve invasão das raízes na tubulação de esgoto. Também foi evidenciado que os moradores não possuem muito conhecimento à respeito da agressividade das raízes das árvores por eles plantadas, o que contribui para a justificação do fato das manifestações patológicas.

Diante dessas circunstâncias pode-se observar que a população tem conhecimento da importância da arborização, logo é essencial o investimento em educação ambiental, já que o conhecimento é cultivado como sendo um dos pilares para o desenvolvimento. Além disso, conclui-se que deve ser observada a distância da árvore em relação às calçadas e ao interior da residência, e demais locais onde possam gerar problemas. O tipo de espécie à ser plantada é extremamente relevante, pois deve-se lembrar que uma muda cresce e que os moradores devem respeitar o tamanho da copa e a estrutura de raízes das árvores para evitar problemas futuros. É necessário que realizem alguns cuidados no momento do plantio, visto que algumas espécies podem crescer e causar incovenientes como os que já foram citados. Recomenda-se que as espécies exóticas sejam substituidas por espécies nativas, pois apesar da facilidade da adaptação de algumas espécies exóticas, seu plantio está causando problemas urbanos.

Portanto, não é necessário só plantar árvores, é preciso que os cidadãos percebam a importância de se escolher corretamente a espécie e o manuseio adequado para que haja, de fato, a melhoria na qualidade de vida da população. Contudo, deve ser priorizado o plantio de espécies nativas da região, que não possuam a raíz agressiva, e devem ser realizados estudos para que os inconvenientes não ultrapassem os beneficios. 


\section{REFERÊNCIAS}

AGUIAR, F. O, Análise de métodos para avaliação da qualidade de calçadas, $124 \mathrm{f}$. Dissertação apresentada ao Programa de Pós-Graduação em Engenharia Urbana, na Universidade Federal de São Carlos, como parte dos requisitos para a obtenção do título de Mestre em Engenharia Urbana. Universidade Federal de São Carlos, São Carlos, 2003.

ARANHA, P. M. S. Contribuição Ao Estudo Das Manifestações Patológicas Em Estruturas De Concreto Armado Na Região Amazônica,110 f. Dissertação Apresentada Ao Curso De Pós-Graduação Em Engenharia Civil Da Universidade Federal Do Rio Grande Do Sul, Como Parte Dos Requisitos Para Obtenção Do Título De Mestre Em Engenharia. Universidade Federal Do Rio Grande Do Sul, Porto Alegre, 1994.

ASSOCIAÇÃO BRASILEIRA DE NORMAS TÉCNICAS. ABNT NBR 9050: Acessibilidade a edificações, mobiliário, espaços e equipamentos urbanos. Rio de Janeiro, p. 3. 2015.

BEZERRA C. S; COSTA J. M. O; SILVA A. B, Levantamento Florístico e Comparação Quali-quantitativa da Arborização em Áreas Verdes Públicas da Cidade de Monteiro-PB. ENCICLOPÉDIA BIOSFERA, Centro Científico Conhecer - Goiânia, v.13 n.24; p. 650-660 2016.

BRASIL. Instituto Brasileiro de Floresta. Mudas de Canafístula. Disponivel em: $<$ https://www.ibflorestas.org.br/canafistula?keyword $=\% 2$ Barvore\%20\%2Bcanafistula\&creative $=329460796078 \&$ gclid $=$ CjwKCAjw-LrBRB6EiwAhh1yX30C1v5xTlv_Xuivsu6IJYIIHbI36PV0tmiG2H3RarHBwJilX-

fE8RoCLp0QAvD_BwE>. Acesso em: 02, set. 2019, 14:24.

BRASIL. Lei n ${ }^{\circ}$ 9503, de 23 de setembro de 1997. Institui o Código de Trânsito Brasileiro. Código De Trânsito Brasileiro. Brasília, DF.

CALISTO. A; koswoski. R. Efeito do recalque diferencial de fundações em estruturas de concreto armado e alvenaria de vedação. Estudo de caso. Trabalho de Conclusão de Curso de graduação apresentado à disciplina de Trabalho de Conclusão de Curso 2, do curso de Engenharia de Produção Civil, do Departamento Acadêmico de Construção Civil - DACOC -da Universidade Tecnológica Federal do Paraná - UTFPR, como requisito parcial para a obtenção do grau de Bacharelado em Engenharia de Produção Civil. Curitiba, Paraná, 2015.

CARVALHO, A. A; SILVA, L. F; LIMA, A. P; SANTOS, T. P, A Inviabilidade do Ficus (Ficus Benjamina L.) para Arborização Viária. XIII JORNADA DE ENSINO, PESQUISA E EXTENSÃO - JEPEX - UFRPE: Recife, 09 a 13 de dezembro, 2013.

DANTAS I. C; SOUZA C. M. C, Arborização urbana na cidade de Campina Grande - PB: Inventário e suas espécies. Revista de Biologia e Ciências da Terra, vol. 4, núm. 2, segundo semestre, 2004.

GONÇALVEZ, A; MANEGUETTI, K. S, Projeto de arborização como patrimônio da Cidade. Ambiente Construído, Porto Alegre,v. 15, n. 1,p. 99-118, jan./mar. 2015.

DUTRA, A. S.; MEDEIROS FILHO, S.; TEÓFILO, E. M.; DINIZ, F. O. Germinação de sementes de Senna siamea (Lam.) H.S. Irwin E Barneby - Caesalpinoideae, Revista Brasileira de Sementes, Londrina-PR, v. 29, n. 1, p. 160-164, 2007.

INSTITUTO BRASILEIRO DE GEOGRAFIA E ESTATÍSTICA (IBGE). Disponível em: < https://cidades.ibge.gov.br/brasil/pb/monteiro/panorama>. Acesso em: 21, fev. 2020, 12:53.

JUNQUEIRA, H; PEETZ, M. O déficit da arborização urbana no Brasil. [S.I]: Jardim Cor, 2012. Disponível em: < http://www.jardimcor.com/arvores/o-deficit-da-arborizacao-urbana-no-brasil/>. Acesso em: 14, set. 2019, 13:30.

LOPES. M. S; TEIXEIRA. R. D. Patologia Das Edificações: Proposta De Recuperação Do Centro Municipal De Cultura Museu Willy Zumblick Da Cidade De Tubarão/Sc. Trabalho de Conclusão de Curso apresentado ao Curso de Graduação em Engenharia Civil da Universidade do Sul de Santa Catarina como requisito parcial à obtenção do título de Bacharel em Engenharia Civil. Tubarão, Santa Catarina, 29 de novembro de 2017.

MARTELLI, A; SANTOS JR A. R, Arborização Urbana do município de Itapira - SP: perspectivas para educação ambiental e sua influência no conforto térmico. Revista do Centro de Ciências Naturais e Exatas - UFSM Santa Maria Revista Eletrônica em Gestão, Educação e Tecnologia Ambiental, v. 19, n. 2, p. 1018-1031, mai-ago. 2015. 
MILITITSKY. J; CONSOLI. N. C; SCHNAID. F. Patologia das Edificações. 2. ed. São Paulo: Oficina de Textos, 2005.

RENK. M. B. Análise Da Região De Transição Entre Calçadas E Edificações Conforme Os Requisitos De Acessibilidade. Programa De Pós-Graduação Em Estruturas Construção Civil. Brasília - DF, p. 133, dezembro de 2018.

SALTON, J. C.; TOMAZI, M. Sistema radicular de plantas e qualidade do solo. Dourados: Embrapa Agropecuária Oeste; 2014. (Comunicado técnico, 198).

SILVA, O. H; LOCASTRO, J. K; SANCHES, S. P; ANGELIS NETO, G; ANGELIZ, B. L. D; CAXAMBÚ, M. G, Avaliação da arborização viária da cidade de São Tomé, Paraná.. Ciência Florestal, v. 29, n. 1, p. 371-384, jan./mar., 2019.

VOLPE-FILIK, A, Trincas nas calçadas e espécies muito utilizadas na arborização: comparação entre Sibipiruna (Caesalpinia pluviosa Dc.) e Falsa-murta (Murraya paniculata (L.) Jacq.), no município de Piracicaba/SP, 97 f. Tese apresentada para obtenção de título de Doutor em Agronomia. Área de concentração: Fitotecnia- Universidade de São Paulo, Piracicaba, 2009.

ZEA, C. J. D. et al. Levantamento e diversidade da arborização urbana de Santa Helena, no semiárido da Paraíba. Agropecuária Científica no Semiárido, Patos, v. 11, n. 4, p. 54-62, 2015. 